\title{
INVESTIMENTOS AVALIADOS PELO MÉTODO DA EQUIVALÊNCIA PATRIMONIAL - ERRO NA CONTABILIZAÇÃO DE DIVIDENDOS QUANDO EXISTEM LUCROS NÃO REALIZADOS*
}

\author{
ARIOVALDO DOS SANTOS \\ Prof. Titular do Depto. de Contabilidade e \\ Atuária da FEA-USP - SP \\ E-mail: arisanto@usp.br
}

\author{
ITAMAR MIRANDA MACHADO \\ Coordenador Geral dos Cursos de \\ Graduação da Faculdade Ibmec - MG \\ E-mail: itamarm@uol.com.br
}

\section{RESUMO}

Sempre que há transações comerciais envolvendo a investida e a investidora pode ocorrer a figura do Lucro Não Realizado - LNR. Quando a controlada vende qualquer ativo com lucro para a controladora e essa ainda não o revendeu para terceiros, dizse que, para o grupo econômico, esse lucro ainda não foi realizado. Ocorre que pode acontecer de a controlada distribuir esse lucro e, assim, para a controladora haverá o recebimento antecipado de dividendos. Este estudo aborda as práticas contábeis quando ocorre a distribuição desse lucro e a forma de apresentação desses dividendos antecipados nas demonstrações individuais da controladora e da controlada; aborda, também, possíveis reflexos na elaboração de demonstrações consolidadas. Como se trata de um tema ainda não discutido pela classe contábil, não previsto na legislação brasileira e na literatura técnica, este trabalho tem como objetivo dar uma contribuição ao assunto, buscando respostas para três questões: a primeira está relacionada à adequação ou não da forma atualmente utilizada para a contabilização de dividendos provenientes de lucros que ainda não tenham sido realizados para - grupo econômico. A segunda busca alternativas para a contabilização adequada desses dividendos. A terceira diz respeito à forma de apresentação das demonstrações contábeis quando há pagamento de dividendos oriundos de LNR.

Palavras-chave: Consolidação; Demonstrações Contábeis; Dividendos; Lucros Não Realizados e Método de Equivalência Patrimonial.

\begin{abstract}
Whenever there are commercial transactions involving investees and investors, the figure of unrealized profit may come up. When the subsidiary sells any asset to the controlling company with a profit, and the latter has not sold it yet to a third part, it is said that, for the economic group, this profit has not been realized yet. It may happen that the subsidiary distributes this profit and, thus, the controlling company will receive dividends early. This study deals with accounting practices of financial statements when this profit is distributed, as well as how these anticipated dividends should be presented on the individual statements of controlling company and subsidiary; it also treats possibility of reflex in the consolidated financial statements. As this subject has not been discussed in the accounting sphere, neither has it been included in Brazilian legislation nor technical literature, this research aims to contribute to the subject by seeking to answer three questions: the first is related to the adequacy or not of the current accounting treatment of dividends from profits that have not been realized yet by the economic group. The second question seeks alternatives to the adequate accounting treatment of these dividends. The third refers to the presentation of financial statements in case of dividend payment from unrealized profits.
\end{abstract}

Keywords: Consolidation; Financial Statements; Dividends; Unrealized Profits and Equity Method.

Recebido em 15 Mar. 2005 • Aceito em 28 Jun. 2005 • 2a versão aceita em 10 Ago. 2005

* Este artigo é uma adaptação do trabalho originalmente apresentado no XXVIII Congresso ENANPAD, realizado em Curitiba-PR, no período de 25 a 29.09.2004. 


\section{INTRODUÇÃO}

Um dos principais objetivos da Contabilidade é o de oferecer informações a respeito da vida das empresas. A melhoria da qualidade dessas informações tem sido objeto de muitos estudos e pesquisas dos órgãos nacionais e internacionais, assim como de professores, estudantes e profissionais da área contábil.

Nesse sentido, a forma de avaliar os investimentos permanentes em outras sociedades tem merecido, ao longo dos anos, bastante atenção, pois as empresas, além de suas próprias atividades, também participam de outras empresas. Regra geral, essa participação tem como objetivo a diversificação de riscos e a otimização de seu resultado global.

No momento de se avaliar os investimentos efetuados em outras sociedades, poder-se-ia ter dois pontos de partida: demonstrações contábeis individuais ou consolidadas. Nas individuais, os resultados desses investimentos são avaliados pelo Método de Equivalência Patrimonial - MEP. Esse método consiste em reconhecer os efeitos da variação do patrimônio líquido de cada controlada, coligada e equiparada no exercício social em que ocorre, independentemente de sua realização financeira. Esse reconhecimento é proporcional ao percentual de participação da investidora no capital de cada investida, conforme determina a Comissão de Valores Mobiliários - CVM, no parágrafo único, do Art.1ํ da Instrução 247/96.

Martins (1997, p. 1) menciona que

[...] é comum nessa forma de avaliação (equity method) a utilização na língua inglesa, da expressão one line consolidation. Ou seja, a equivalência patrimonial é uma forma simplificada de consolidação numa linha só, já que, ajustando-se uma única linha do balanço, a dos investimentos, produz-se a incorporação da parcela do lucro ou do prejuízo da investida que cabe à investidora.

A literatura tem mostrado que as demonstrações consolidadas são mais adequadas, pois eliminam todos os saldos e quaisquer operações realizadas entre empresas do mesmo grupo.

Consolidar consiste em agrupar as demonstrações contábeis das empresas controladas às demonstrações da controladora. Segundo a FIPECAFI (2003, p. 462),

o objetivo da consolidação é apresentar aos leitores, principalmente acionistas e credores, os resultados das operações e a posição financeira da sociedade controladora e suas controladas, como se o grupo fosse uma única empresa que tivesse uma ou mais filiais ou divisões. Isso permite uma visão mais geral e abrangente e melhor compreensão do que inúmeros balanços isolados de cada empresa.

Esse tipo de demonstração é utilizado nos Estados Unidos há cerca de um século. Em outros países iniciou-se bem mais tarde, aparecendo na legislação inglesa apenas em 1947, na alemã em 1965, no Japão em 1976 e na francesa em 1985.

A obrigatoriedade de consolidação das demonstrações contábeis e de avaliação de investimentos pelo MEP, no Brasil, foi introduzida, de forma ampla, pela Lei no 6.404, de 15 de dezembro de 1976. A Comissão de Valores Mobiliários - CVM, autorizada por essa mesma lei, pode e tem expedido normas a respeito desses assuntos. $O$ processo de regulamentação, pela CVM, iniciou-se pela Instrução no 15 de 1980. Em março de 1996, a Instrução de no 247 apresentou algumas inovações como, por exemplo, a consolidação proporcional e a inversão na forma de cálculo do MEP, esta última comentada mais à frente. E ainda, a Instrução no 285 , de 31 de julho de 1998, alterou parte da Instrução № 247, no que se refere às condições e formas de amortização do ágio ou deságio na aquisição de investimentos avaliados por equivalência patrimonial.

\section{A IMPORTÂNCIA DO TEMA}

Nos últimos anos, houve um expressivo aumento de empresas que passaram a ter investimentos permanentes em outras sociedades. Em função disso, a quantidade de empresas que passou a adotar o Método de Equivalência Patrimonial e apresentar demonstrações consolidadas aumentou significativamente, principalmente em virtude do intenso período de privatizações por que passou o Brasil. Em 1995, dentre as 550 maiores empresas (500 privadas e 50 estatais), listadas na edição de Melhores e Maiores, da Editora Abril, 88 apresentavam demonstrações consolidadas; em 2003, esse número saltou para 117 empresas, com aumento de $33 \%$. Empresas dos mais variados segmentos adquiriram o controle de empresas de telecomunicações, saneamento, energia, concessões de rodovias e ferrovias etc.

A KPMG Brasil (2005) divulgou estudo feito por ela, intitulado Fusões \& Aquisições, que mostra o crescimento das aquisições no Brasil da década de 90 para cá. Segundo a pesquisa, na década de 90 houve um crescimento acumulado de $134 \%$ no número de fusões e aquisições em relação à década anterior, sendo que $61 \%$ das operações envolveram 
investimentos estrangeiros. A pesquisa mostra, ainda, que nos últimos 10 anos (1995 a 2004) ocorreram 3.021 transações desse tipo.

Em função desse alto número de aquisições e fusões de empresas, torna-se ainda mais importante verificar como os investimentos de caráter permanente em outras sociedades devem ser reconhecidos na investidora e, também, como demonstrar a situação econômica e financeira de entidades que, embora juridicamente separadas, representam uma única entidade econômica. Através das demonstrações consolidadas é possível avaliar um grupo econômico.

Um aspecto relevante nessas uniões de empresas é a cadeia produtiva que muitas vezes se estabelece. Por exemplo, uma montadora de automóveis pode ter participações societárias em concessionárias que revendem seus veículos, em empresas de autopeças, de pneus e até mesmo em instituição financeira com o objetivo de financiar a venda dos automóveis, como são os casos de algumas montadoras aqui no Brasil.

É natural que empresas de um mesmo grupo econômico efetuem transações comerciais entre si. Essas operações são apresentadas nas demonstrações individuais, mas devem ser excluídas das demonstrações consolidadas, pois só assim refletirão a real situação econômico-financeira do grupo.

Assim, quando ocorre a transação de venda de ativos entre as controladas e coligadas, e entre elas e a investidora, pode aparecer a figura do que se convencionou chamar de lucros não realizados. Nesses casos, considera-se o resultado dessa venda como não tendo sido realizado, pois houve uma transação apenas doméstica (intercompanhias), não existindo, portanto, resultado econômico para o grupo. Esse resultado só será considerado realizado quando tais ativos forem revendidos a terceiros.

A distribuição de resultados não realizados, oriundos de operações intercompanhias, dentro de um mesmo grupo, constitui-se no objetivo central deste estudo.

\section{CARACTERIZAÇÃO DO PROBLEMA, METODOLOGIA DE PESQUISA E OBJETIVO}

As demonstrações contábeis têm se mostrado como excelente instrumento de avaliação para qualquer tipo de entidade, principalmente aquelas cujo objetivo, dentre outros, é a obtenção de lucros. Para o caso de se avaliar a performance econômico-financeira de grupos econômicos, as demonstrações consolidadas, também, têm sido indicadas como bastante adequadas.
Nas transações comerciais entre empresas que fazem parte de um mesmo grupo econômico, surgem algumas questões que merecem destaque pelas suas peculiaridades. As entidades são individualmente responsáveis pela gestão e pela distribuição de resultados auferidos em suas operações. A Lei das Sociedades por Ações fixa critérios de distribuição de resultados, principalmente no capítulo relativo às formas de cálculos de dividendos obrigatórios e mínimos, e não há qualquer referência ou restrição relativas às distribuições de resultados efetuadas por empresas controladas, mesmo que esses resultados ainda permaneçam no ativo da controladora.

Assim, pode acontecer de a controlada distribuir dividendos relativos a lucros gerados em função de vendas para a própria controladora. Nesse caso, enquanto a controladora mantiver os ativos adquiridos da controlada, significará que o lucro que estará sendo distribuído ainda não foi realizado para o grupo econômico. Essas operações entre controlada e controladora são legais, normais e usuais no mundo dos negócios, pois ambas são entidades juridicamente independentes. Em outras palavras, para a controlada o lucro foi realizado e, portanto, poderá ser distribuído, seja por força de lei, de estatuto ou, até mesmo, por iniciativa dos órgãos responsáveis pela gestão da empresa.

Deve-se ressalvar que, para os acionistas não controladores, os resultados de operações intercompanhias são considerados realizados no momento em que ocorrem, mesmo que ainda permaneçam nos ativos da controladora. Assim, se a controlada distribuir tais resultados, tanto os acionistas não controladores quanto o controlador receberão suas respectivas parcelas do lucro na forma de dividendos.

De acordo com as práticas contábeis atualmente adotadas no Brasil, regra geral, o registro do recebimento de dividendos pode ter dois tratamentos diferenciados: como receitas de dividendos ou baixa de investimentos. A hipótese de registro como receita de dividendos está prevista e é praticada pelas empresas que avaliam seus investimentos pelo Método do Custo. Em verdade essa forma de avaliação de investimentos acaba por reconhecer as receitas de dividendos pelo regime de caixa. As empresas que avaliam seus investimentos pelo Método de Equivalência Patrimonial, por reconhecerem os respectivos resultados pelo regime de competência, quando do recebimento de dividendos baixam os valores da própria conta de investimentos.

Uma das principais caracterizações de um trabalho de pesquisa está na indicação prévia relativa aos objetivos e questões que se pretende atingir ou 
responder. Também deve ser levada em consideração a escolha de prioridades, principalmente por que é muito comum abrir-se uma enorme quantidade de questões que poderiam ser objeto de pesquisa.

Lakatos e Marconi (1982), ao tratarem dos objetivos e questões que devem nortear qualquer trabalho científico, ensinam que: "O problema, assim, consiste em um enunciado explicitado de forma clara, compreensível e operacional, cujo melhor modo de solução ou é uma pesquisa ou pode ser resolvido por meio de processos científicos". Assim, este trabalho terá como objetivo principal buscar respostas para três questões:

1. a forma atualmente utilizada para a contabilização de recebimento de dividendos, provenientes de lucros que ainda não tenham sido realizados para o grupo econômico, é adequada?

2. existem alternativas para a contabilização adequada dos dividendos recebidos e que sejam oriundos de lucros ainda não realizados pelo grupo econômico?

3. a forma de apresentação das demonstrações consolidadas, quando há pagamento de dividendos oriundos de lucros não realizados, é adequada?

Deve-se acrescentar que neste trabalho não se estabeleceram quaisquer hipóteses, principalmente porque o rigor metodológico nem sempre as exige. Diante disso, utiliza-se, neste estudo, a conjugação da pesquisa bibliográfica e da exploratória. Martins (2000) define essas pesquisas da seguinte forma:

Pesquisa bibliográfica: trata-se de estudo para conhecer as contribuições científicas sobre determinado assunto. Tem como objetivo recoIher, selecionar, analisar e interpretar as contribuições teóricas já existentes sobre determinado assunto.

Pesquisa exploratória: trata-se de abordagem adotada para a busca de maiores informações sobre determinado assunto. Possui um planejamento flexível, e é indicada quando se tem pouco conhecimento do assunto.

Como se trata de um tema novo, ainda não discutido pela classe contábil, não previsto na legislação brasileira e na literatura técnica, portanto sem precedentes, neste trabalho será utilizada, principalmente, a pesquisa exploratória, uma vez que se procurará apresentar alternativas de soluções para um assunto que ainda não foi explorado.

\section{CONSOLIDACÃO COM LUCROS NÃO REALIZÁDOS NOS ATIVOS}

Quando ocorre a transação de venda de ativos entre as controladas e coligadas e entre elas e a investidora e se esses ativos ainda não tiverem sido revendidos para terceiros até a data do encerramento do exercício, considera-se que o resultado dessa venda não foi realizado, pois houve uma transação apenas doméstica (intercompanhias), não havendo, portanto, resultado econômico na análise do grupo. Esse resultado será considerado realizado somente quando esses ativos forem revendidos a terceiros. Assim, enquanto permanecer no balanço da controladora, considera-se que o Lucro não foi Realizado.

Portanto, nas demonstrações consolidadas, quando uma empresa controlada vende para a controladora e a mercadoria permanece em seu estoque, ou seja, ainda não foi revendida para terceiros, o lucro que a controlada obteve na venda tem que ser eliminado contra o estoque da controladora. $\mathrm{O}$ objetivo dessa eliminação é espelhar o real valor do estoque adquirido de terceiros, já que o balanço consolidado deve apresentar os valores como se controladora e controlada fossem uma única entidade.

Mais uma vez deve-se ressalvar que para os acionistas não controladores não faz qualquer diferença para quem foram vendidos os estoques da empresa da qual participam. As operações realizadas entre a controlada e a controladora, para os não controladores, são, como quaisquer outras, realizadas com terceiros. É importante destacar que a Lei das S/As e a CVM divergem quanto à forma do cálculo do resultado de equivalência patrimonial. Pelas regras da lei, primeiro deduz-se o resultado não realizado do patrimônio líquido e depois aplicase o percentual de participação; a CVM determina o contrário: primeiro aplica-se o percentual de participação, depois exclui-se o lucro não realizado. $O$ quadro 1 mostra a diferença na forma de calcular o resultado de equivalência patrimonial quando ocorre resultado não realizado.

A forma determinada pela CVM é mais adequada, pois elimina o resultado não realizado, mas preserva a parte do resultado que pertence aos não controladores. Já a forma utilizada pela lei apresenta um equívoco quando há participação de não controladores, pois, ao eliminar todo o resultado não realizado antes da aplicação do percentual de participação, acaba por considerar que esse é um resultado não realizado, tanto para a controladora quanto para os demais investidores. Isso não é correto, porque só existe a figura do lucro não realizado entre as empresas do grupo; para os demais investidores não importa para quem os ativos foram ven- 


\begin{tabular}{|cc|}
\hline Pela Lei das S/As & Pela CVM \\
\hline Patrimônio Líquido da Investida & Patrimônio Líquido da Investida \\
\hline$(-)$ Resultado Não Realizado & $\times$ Percentual de Participação \\
\hline = Patrimônio Líquido Ajustado & Subtotal \\
\hline$\times$ Percentual de Participação & $(-)$ Lucro Não Realizado \\
\hline$=$ Valor atual do Investimento & $=$ Valor atual do Investimento \\
\hline$(-)$ Valor do Investimento Registrado & $(-)$ Valor do Investimento Registrado \\
\hline$=$ Resultado de Equivalência Patrimonial & $=$ Resultado de Equivalência Patrimonial
\end{tabular}

Quadro1 - Comparação do Cálculo do Resultado de Equivalência Patrimonial - Lei 6.404/76 × CVM

didos. Portanto, para eles, a operação foi efetivada normalmente, ou seja, o lucro foi realizado.

Outro ponto de divergência é que a lei menciona resultados não realizados, portanto, lucros ou prejuízos, enquanto a CVM menciona apenas lucros não realizados, deixando claro, no parágrafo 2 da Instrução no 247/96, que os prejuízos não realizados não devem ser eliminados. A forma determinada pela CVM está em consonância com o Princípio da Prudência, pois, ao se eliminar apenas o lucro, se estará atribuindo menor valor ao ativo. Então, por considerar-se tecnicamente mais correto, neste estudo, será adotado o cálculo do resultado de equivalência patrimonial de acordo com as regras estabelecidas pela CVM.

A seguir, será apresentado um exemplo de operação entre controlada e controladora, com a presença do lucro não realizado nos estoques:

Em 31.12.X1 as empresas apresentaram os seguintes Balanços:

\begin{tabular}{|c|c|c|c|c|c|c|c|}
\hline \multirow[b]{2}{*}{ ATIVO } & \multicolumn{2}{|c|}{ Cias. } & \multirow[b]{2}{*}{ Consolidado } & \multirow[b]{2}{*}{ PASSIVO + PL } & \multicolumn{2}{|c|}{ Cias. } & \multirow[b]{2}{*}{ Consolidado } \\
\hline & $x$ & $\mathbf{Y}$ & & & $\mathbf{x}$ & $\mathbf{Y}$ & \\
\hline Banco & 180 & - & 180 & $\begin{array}{l}\text { Participação de } \\
\text { não controladores }\end{array}$ & - & - & $\underline{30}$ \\
\hline Estoque & - & 100 & 100 & Patrimônio Líquido & $\underline{250}$ & $\underline{100}$ & $\underline{250}$ \\
\hline Investimento $-Y$ & 70 & - & - & Capital & 250 & 100 & 250 \\
\hline Total do Ativo & 250 & 100 & 280 & Total do Passivo + PL & 250 & 100 & 280 \\
\hline
\end{tabular}

Informações:

- A Cia. X participa em $70 \%$ da Cia.Y.

- Em X2 a Cia. Y vendeu todo seu estoque valorado em \$100 para a Cia. X por 180.

- A Cia. X não revendeu a mercadoria adquirida.

- Por simplificação, não serão considerados os impostos incidentes sobre as vendas e os lucros. 
Após essa transação, as demonstrações individuais e consolidada são as seguintes:

DRES INDIVIDUAIS E CONSOLIDADA - 31.01.X2

\begin{tabular}{|c|c|c|c|c|c|}
\hline \multirow[b]{2}{*}{ Contas } & \multicolumn{2}{|c|}{ Cias. } & \multicolumn{2}{|c|}{ Eliminações } & \multirow{2}{*}{$\begin{array}{c}\text { Saldos } \\
\text { Consolidados }\end{array}$} \\
\hline & $\mathbf{X}$ & $\mathbf{Y}$ & Débito & Crédito & \\
\hline Receita de Vendas & - & 180 & 180 & & - \\
\hline C.M.V & - & $(100)$ & & 100 & - \\
\hline Lucro Bruto & - & 80 & 180 & 100 & - \\
\hline Res. Equiv. Patrimonial & (24) & & & 24 & - \\
\hline Lucro antes não controladores & (24) & 80 & 180 & 124 & - \\
\hline Participação não controladores & - & & 24 & & (24) \\
\hline Lucro & (24) & 80 & 204 & 124 & (24) \\
\hline
\end{tabular}

\begin{tabular}{|ll|}
\hline Cálculo da Equivalência Patrimonial \\
\hline Patrimônio Líquido da Investida & 180 \\
\hline x Percentual de Participação & $\underline{70 \%}$ \\
\hline Subtotal & $\mathbf{1 2 6}$ \\
\hline (-) Lucro Não Realizado & $\underline{(80)}$ \\
\hline = Valor atual do Investimento & $\mathbf{4 6}$ \\
\hline (-) Valor do Investimento em X1 & $\underline{(70)}$ \\
\hline = Resultado de Equivalência Patrimonial & (24) \\
\hline
\end{tabular}

A equivalência patrimonial negativa de $\$ 24$ refere-se à participação de $30 \%$ dos demais investidores sobre o lucro não realizado $=\$ 80 \times 30 \%$, ou seja, ao excluir todo o lucro não realizado, de acordo com o critério estabelecido pela CVM, a controladora reconheceu que para os demais investidores essa parcela do lucro é considerada realizada. Portanto, além de não reconhecer sua parcela sobre o lucro não realizado $(\$ 80 \times 70 \%=\$ 56)$, reconheceu que para o grupo (controladora + investida) a parte do lucro que pertence aos acionistas não controladores deve ser tratada como "prejuízo".

BALANÇOS INDIVIDUAIS E CONSOLIDADO - 31.01.X2 - Lucro Não Realizado nos Estoques

\begin{tabular}{|c|c|c|c|c|c|c|}
\hline \multirow[b]{2}{*}{ ATIVO } & \multicolumn{2}{|c|}{ Cias. } & \multicolumn{3}{|c|}{ Eliminações } & \multirow{2}{*}{$\begin{array}{c}\text { Saldos } \\
\text { Consolidados }\end{array}$} \\
\hline & $x$ & $\mathbf{Y}$ & Débito & & Crédito & \\
\hline Caixa e Bancos & - & 180 & & & & 180 \\
\hline Estoque & 180 & - & & & 80 & 100 \\
\hline Investimento $-Y$ & 46 & - & 24 & $\mathrm{C}$ & 70 & $\mathrm{~b}$ \\
\hline Total & 226 & 180 & 24 & & 150 & 280 \\
\hline
\end{tabular}




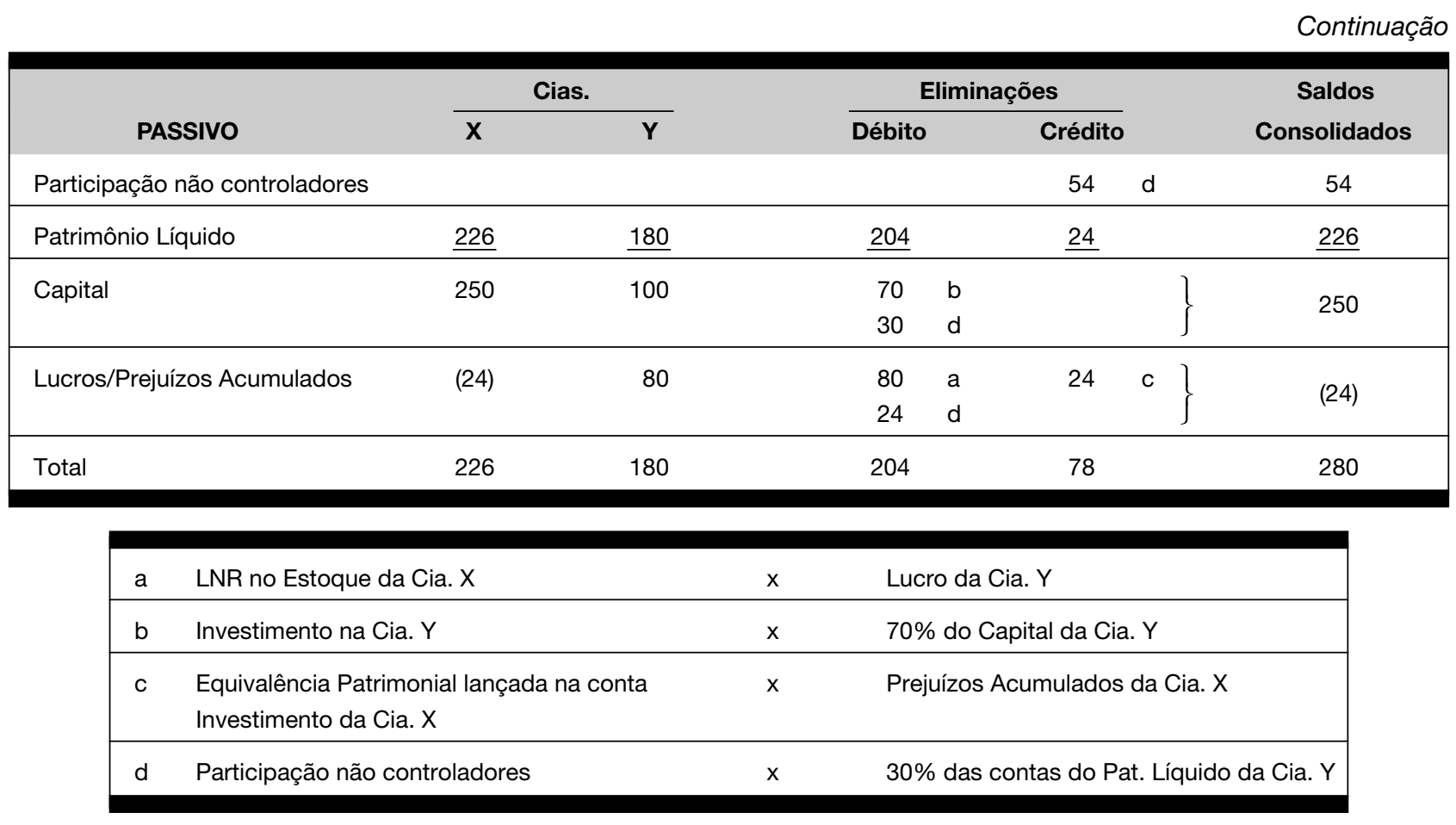

Quadro 2 - Explicações das Eliminações no Balanço

\subsection{E se as Empresas Distribuírem Dividendos quando há Lucros Não Realizados nos Estoques?}

Nesse tópico, apresentam-se duas formas de contabilização dos dividendos quando há lucros não realizados: a primeira é aquela que tradicionalmente tem sido utilizada, mas que poderá apresentar relevante imperfeição; a segunda é uma alternativa proposta no sentido de melhor demonstrar a contabilização desse tipo de operação.

\subsubsection{Forma Tradicional de Contabilização}

No exemplo desenvolvido anteriormente, chamou-se a atenção para o reconhecimento de uma despesa de equivalência patrimonial de \$24. Isso, conseqüentemente, reduziu o valor dos investimentos da empresa $X$ em $Y$ para $\$ 46$. Admitindo-se que a controlada $Y$ distribua integralmente o lucro de $\$ 80$, a controladora receberá a quantia de $\$ 56(70 \%$ de $\$ 80$ ) e no momento que registrar essa operação, utilizando-se da forma tradicional de contabilização, a conta relativa a Investimentos em Y se apresentará com saldo negativo de $\$ 10$. Isso por si só já indica a prática contábil incorreta que tem sido utilizada.

A prática incorreta referida no parágrafo anterior está na forma de se registrar o dividendo recebido contra a conta de Investimentos; essa prática só pode ser considerada correta quando não há lucros não realizados nos ativos da controladora. Quando esses lucros existem, ao se efetuar o registro como baixa na conta de Investimentos, quando do recebimento de dividendos, na verdade o que se estará registrando é uma devolução do aporte de capital efetuado, mais um lucro ainda inexistente; é isso que transforma o saldo de investimentos em valores negativos. É nesse momento que aparece a perplexidade: ora como pode uma conta de investimento estar com valor negativo? Fica, no mínimo, muito estranho a Cia. X dizer: "temos menos $\$ 10$ investidos na Cia. $Y$ ". Nem mesmo quando a investida está com passivo a descoberto isso ocorre, pois a equivalência patrimonial é registrada até se chegar ao investimento zero. A Instrução no $247 / 96$ da CVM, em seu artigo 16 , parágrafo único, menciona que "o resultado negativo da equivalência patrimonial terá como limite o valor contábil do investimento". Isso ocorre porque o máximo que o investidor pode perder é o valor do investimento realizado. A FIPECAFI (2003, p. 196), a esse respeito, cita que

Essa prática decorre do fato de que, teoricamente, o valor máximo de perda aplicável à investidora é o investimento total efetivado. Assim, quando o valor do investimento pela equivalência patrimonial estiver zerado, a investidora terá reconhecido a totalidade do investimento feito como perda. 
Aqui se deve ressaltar que, em determinadas situações, como, por exemplo, quando a investidora é responsável pelas dívidas da investida ou para que não haja prejuízos à imagem das empresas do grupo, será necessária a formação de provisão que se destine à cobertura desses possíveis passivos.
Para efeitos didáticos, a seguir são apresentados os balanços individuais das Cias. $\mathrm{X}$ e $\mathrm{Y}$ e o consolidado, considerando-se a distribuição do dividendo sobre o lucro não realizado:

BALANÇOS INDIVIDUAIS E CONSOLIDADO - 31.01.X2 - Distribuição do LNR

\begin{tabular}{|c|c|c|c|c|c|}
\hline \multirow[b]{2}{*}{ ATIVO } & \multicolumn{2}{|c|}{ Cias. } & \multicolumn{2}{|c|}{ Eliminações } & \multirow{2}{*}{$\begin{array}{c}\text { Saldos } \\
\text { Consolidados }\end{array}$} \\
\hline & $\mathbf{x}$ & $\mathbf{Y}$ & Débito & Crédito & \\
\hline Caixa e Bancos & 56 & 100 & & & 156 \\
\hline Estoque & 180 & - & & 80 & 100 \\
\hline Investimento - Y & $(10)$ & - & & & - \\
\hline - Investimento (aporte) & 70 & & & 70 & - \\
\hline - Res.Equiv.Patrimonial & (24) & & 24 & & - \\
\hline - Dividendos Recebidos & (56) & & 56 & & - \\
\hline Total & 226 & 100 & 80 & 150 & 256 \\
\hline
\end{tabular}

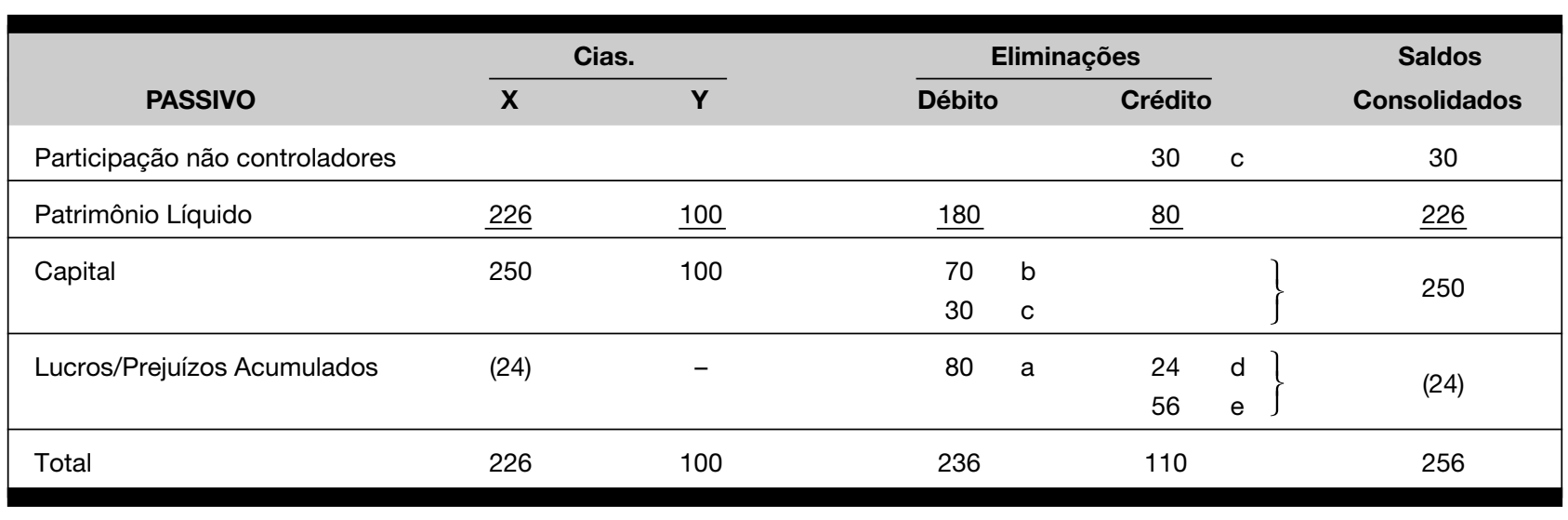

$\mathrm{Na}$ seqüência são apresentadas algumas observações que são consideradas importantes:

1) No balanço de $X$, a conta de InvestimentoCia. $Y$ foi decomposta para melhor ilustrar os lançamentos de eliminações.

2) Como a distribuição de dividendos não afeta o resultado do exercício, a DRE deixou de ser reapresentada, pois ela é a mesma apresentada anteriormente.

3) O patrimônio Líquido da Investida, antes da distribuição do dividendo, era de $\$ 180$ (Capital de $\$ 100+\$ 80$ de Lucro).

4) Os lucros acumulados de $\$ 80$ foram integralmente distribuídos, sendo $-70 \%$ para a controladora X e $30 \%$ para os não controladores.
Pode-se reafirmar que, da forma que vem sendo efetuado, o registro do recebimento de dividendos relativos a lucros não realizados tem se mostrado uma prática contábil incorreta.

\subsubsection{Formas Propostas de Contabilização}

Como visto anteriormente, a prática atual de se registrarem os dividendos relativos a lucros ainda não realizados na controladora não está correta. Assim, se faz importante a reflexão sobre formas alternativas para esse registro. Na seqüência, serão apresentadas as demonstrações da controladora, controlada e consolidado utilizando-se duas possíveis formas alternativas para esse registro. Depois de se reapresentar essas demonstrações, introduzir-se-ão comentários que poderão auxiliar no entendimento e escolha da forma mais adequada para o referido registro. 
Vale ressaltar, quando existem práticas que não refletem de forma clara a realidade dos fatos, faz-se necessário ousadia nas classificações contábeis no sentido de melhor expressar uma determinada transação, saindo das formas e conceitos convencionais e tradicionais. As alternativas estudadas são apresentadas a seguir.

\subsubsection{Alternativa-1}

Na primeira, a controlada considerará o valor dos dividendos pagos como Dividendos Antecipa- dos, classificando-os em seu a Ativo Circulante ou Realizável a Longo Prazo, pois o termo "Antecipado" pode sugerir a existência de um direito, por isso sua classificação como conta de Ativo. Enquanto a controladora, por estar recebendo de boa fé algo antecipadamente e que, portanto, não terá obrigação de devolver, os consideraria dentro do grupo de Resultados de Exercícios Futuros. Assim, as novas demonstrações seriam as seguintes:

\section{BALANÇO CONSOLIDADO - 31.01.X2 - Distribuição do LNR}

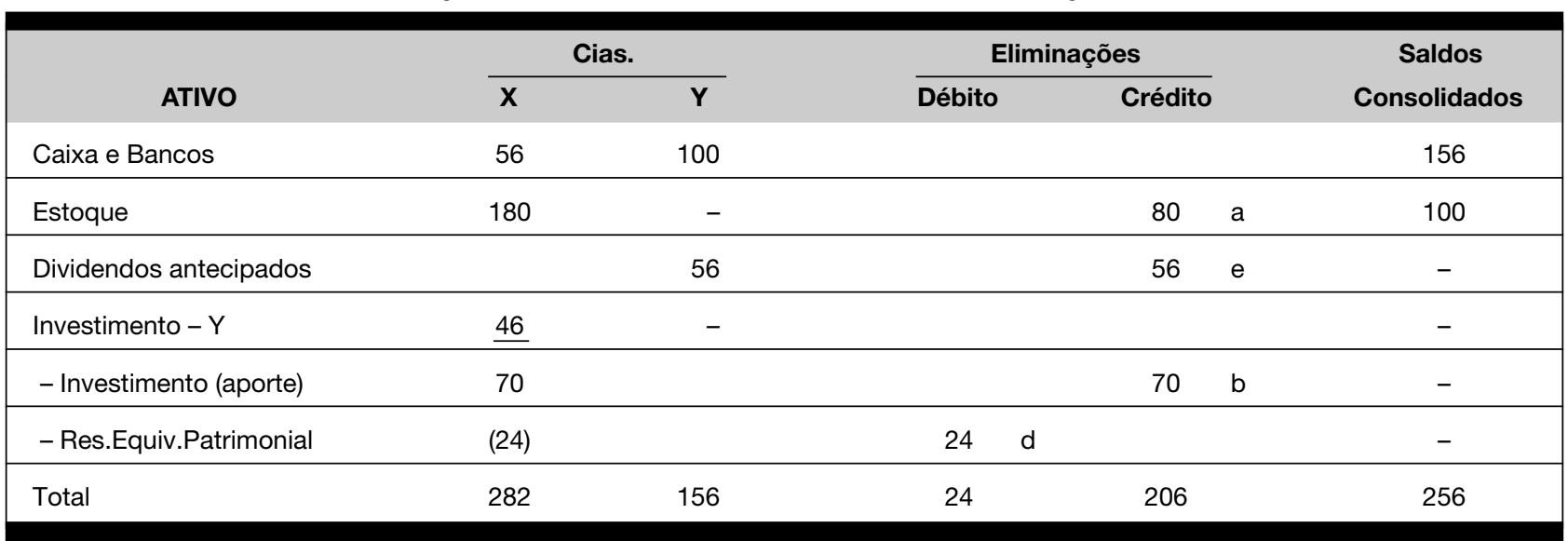

\begin{tabular}{|c|c|c|c|c|c|c|c|}
\hline \multirow[b]{2}{*}{ PASSIVO } & \multicolumn{2}{|c|}{ Cias. } & \multicolumn{3}{|c|}{ Eliminações } & & \multirow{2}{*}{$\begin{array}{c}\text { Saldos } \\
\text { Consolidados }\end{array}$} \\
\hline & $\mathbf{x}$ & $\mathbf{Y}$ & Débito & & Crédito & & \\
\hline Res. de Exercícios Futuros & $\underline{56}$ & & $\underline{56}$ & & & & \\
\hline Dividendos Antecipados & 56 & & 56 & e & & & \\
\hline Participação não controladores & & & & & 30 & c & 30 \\
\hline Patrimônio Líquido & $\underline{226}$ & $\underline{156}$ & 180 & & 24 & & 226 \\
\hline \multirow[t]{2}{*}{ Capital } & \multirow[t]{2}{*}{250} & \multirow[t]{2}{*}{100} & 70 & b & & & \multirow{2}{*}{250} \\
\hline & & & 30 & c & & & \\
\hline Lucros/Prejuízos Acumulados & (24) & 56 & 80 & a & 24 & d & (24) \\
\hline Total & 282 & 156 & 236 & & 54 & & 256 \\
\hline
\end{tabular}

Nesse caso, os saldos consolidados estão bastante adequados, afinal os disponíveis (Caixa e Bancos) e estoques representam os reais valores de ativos que são controlados pela empresa investidora X; o mesmo acontece com os valores que são apresentados no patrimônio líquido consolidado. $\mathrm{O}$ montante de $\$ 226$ representa o capital de $\$ 250$ dos acionistas controladores, menos os $\$ 24$ de lucros que foram distribuídos aos não controladores e que não foram realizados pelo grupo econômico.

A participação dos não controladores de $\$ 30$, nesse caso específico, representa apenas o percentual que esses acionistas têm sobre o capital social e não sobre o patrimônio líquido de $Y$, uma vez que já receberam os dividendos relativos à sua participação no lucro da investida. Essa aparente "diferen- 
ça" poderá provocar dificuldades no entendimento do real significado dessa participação dos não controladores de "Y".

Ainda, nessa alternativa, o balanço individual da Cia. Y ficaria com uma conta ativa denominada "Dividendos Antecipados", que não atenderia aos conceitos daquilo que efetivamente deve ser considerado como genuíno ativo. Além disso, restaria, em seu patrimônio líquido, a conta de "Lucros Acumulados" relativa a lucros que efetivamente já foram distribuídos e, em muitos casos, como nesse exemplo, até pagos. Óbvio que essa alternativa não é adequada.

\subsubsection{Alternativa-2}

Nessa alternativa, na controladora os dividendos recebidos, também, foram tratados dentro de resultados de exercícios futuros, porém na controlada os dividendos antecipados foram considerados dentro de uma conta retificadora do patrimônio líquido.

BALANÇOS INDIVIDUAIS E CONSOLIDADO - 31.01.X2 - Distribuição do LNR

\begin{tabular}{|c|c|c|c|c|c|}
\hline \multirow[b]{2}{*}{ ATIVO } & \multicolumn{2}{|c|}{ Cias. } & \multicolumn{2}{|c|}{ Eliminações } & \multirow{2}{*}{$\begin{array}{c}\text { Saldos } \\
\text { Consolidados }\end{array}$} \\
\hline & $\mathbf{x}$ & $\mathbf{Y}$ & Débito & Crédito & \\
\hline Caixa e Bancos & 56 & 100 & & & 156 \\
\hline Estoque & 180 & - & & 80 & 100 \\
\hline Investimento $-Y$ & $\underline{46}$ & - & & & - \\
\hline - Investimento (aporte) & 70 & & & 70 & - \\
\hline - Res.Equiv.Patrimonial & (24) & & 24 & & - \\
\hline Total & 282 & 100 & 24 & 150 & 256 \\
\hline
\end{tabular}

\begin{tabular}{|c|c|c|c|c|c|c|c|}
\hline \multirow[b]{2}{*}{ PASSIVO } & \multicolumn{2}{|c|}{ Cias. } & \multicolumn{3}{|c|}{ Eliminações } & & \multirow{2}{*}{$\begin{array}{c}\text { Saldos } \\
\text { Consolidados }\end{array}$} \\
\hline & $\mathbf{x}$ & $\mathbf{Y}$ & Débito & & Crédito & & \\
\hline Res. de Exercícios Futuros & $\underline{56}$ & & $\underline{56}$ & & & & - \\
\hline Dividendos Antecipados & 56 & & 56 & e & & & - \\
\hline Participação não controladores & & & & & 30 & c & 30 \\
\hline Patrimônio Líquido & $\underline{226}$ & $\underline{100}$ & $\underline{180}$ & & $\underline{80}$ & & $\underline{226}$ \\
\hline \multirow[t]{2}{*}{ Capital } & \multirow[t]{2}{*}{250} & \multirow[t]{2}{*}{100} & 70 & $b$ & & & \multirow{2}{*}{250} \\
\hline & & & 30 & c & & & \\
\hline Lucros/Prejuízos Acumulados & (24) & 56 & 80 & a & 24 & d & (24) \\
\hline Dividendos Antecipados & & (56) & & & 56 & e & \\
\hline Total & 282 & 100 & 236 & & 110 & & 256 \\
\hline
\end{tabular}

Aqui, os saldos das demonstrações consolidadas são exatamente iguais aos apresentados na primeira alternativa. Porém, a demonstração individual da controlada $Y$ está bem mais adequada do que aquela apresentada anteriormente (alternativa-1). O ativo de $\$ 100$ apresentado na conta de "Caixa e Bancos" e o valor do patrimônio líquido estão, adequadamente, representados; além disso, o valor dos dividendos pagos, antecipadamente, ficaria, de forma bem transparente, evidencia- do. Da mesma forma, no consolidado, o valor de \$30 da participação dos não controladores, nesse caso, representa, exatamente, sua participação de $30 \%$ no patrimônio líquido e não apenas sobre o capital da Cia. Y.

Resta, ainda, a discussão sobre a adequação da utilização do grupo de resultados de exercícios futuros para a classificação do recebimento dos dividendos que se está discutindo. Quer nos parecer que essa utilização é bastante adequada e consis- 
tente com o uso que se vem fazendo desse grupo; porém, entende-se que a utilização de uma conta que estivesse inserida dentro do patrimônio líquido, evidenciando que se trata de lucro ainda não realizado, seria ainda mais adequada. Felizmente, a idéia de inserção de grupo de contas, em que se destaquem lucros não realizados, dentro do patrimônio líquido, já está bastante madura e até já foi incluída no projeto de lei encaminhado ao Governo pela CVM.

\subsubsection{E quando esses Lucros se realizarem?}

Finalmente, admitir-se-á que no mês seguinte (fevereiro) a Controladora tenha revendido, para terceiros, todo o estoque por $\$ 230$ à vista. Portanto, nesse momento, o lucro realizou-se. Nesse período, não houve nenhuma movimentação na controlada. Sendo assim, as novas demonstrações ficaram da seguinte forma:

BALANÇOS INDIVIDUAIS E CONSOLIDADO - 28.02.X2 - Distribuição do LNR

\begin{tabular}{|c|c|c|c|c|c|}
\hline \multirow[b]{2}{*}{ ATIVO } & \multicolumn{2}{|c|}{ Cias. } & \multicolumn{2}{|c|}{ Eliminações } & \multirow{2}{*}{$\begin{array}{c}\text { Saldos } \\
\text { Consolidados }\end{array}$} \\
\hline & $\mathbf{x}$ & $\mathbf{Y}$ & Débito & Crédito & \\
\hline Caixa e Bancos & 286 & 100 & & & 386 \\
\hline Investimento $-Y$ & 70 & - & & 70 & - \\
\hline Total & 356 & 100 & & 70 & 386 \\
\hline
\end{tabular}

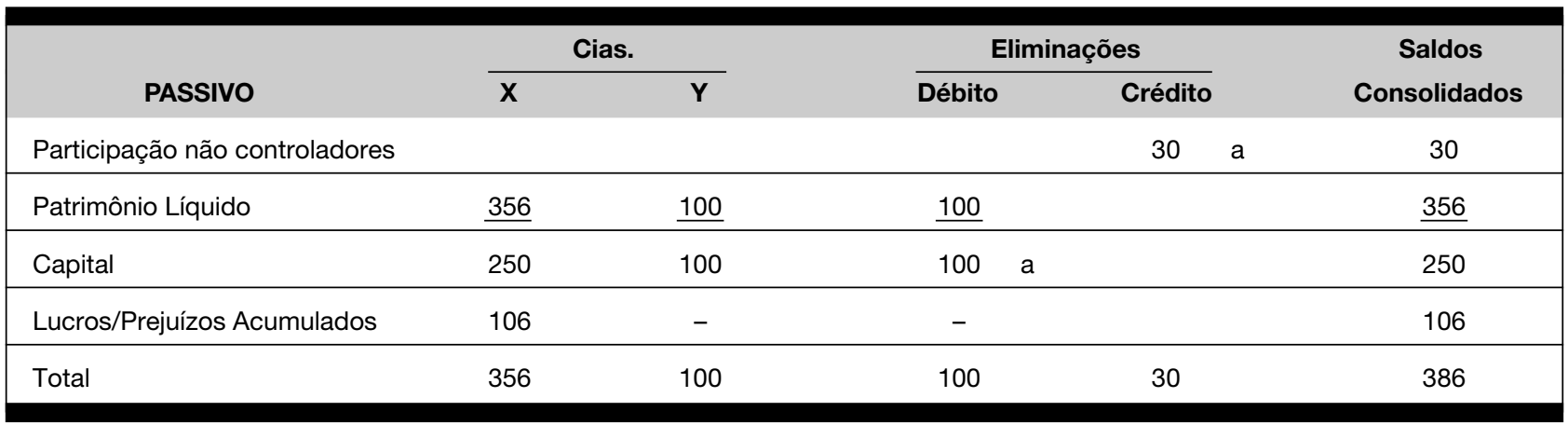

DREs INDIVIDUAIS E CONSOLIDADA - 28.02.X2

\begin{tabular}{|c|c|c|c|c|c|}
\hline \multirow[b]{2}{*}{ Contas } & \multicolumn{2}{|c|}{ Cias. } & \multicolumn{2}{|c|}{ Eliminações } & \multirow{2}{*}{$\begin{array}{c}\text { Saldos } \\
\text { Consolidados }\end{array}$} \\
\hline & $\mathbf{x}$ & $\mathbf{Y}$ & Débito & Crédito & \\
\hline Receita de Vendas & 230 & 180 & 180 & & 230 \\
\hline C.M.V & $(180)$ & $(100)$ & & 180 & $(100)$ \\
\hline Lucro Bruto & 50 & 80 & 180 & 180 & 130 \\
\hline Res. Equiv. Patrimonial & 56 & & 56 & & - \\
\hline Lucro antes não controladores & 106 & 80 & 236 & 180 & 130 \\
\hline Participação não controladores & - & & 24 & & (24) \\
\hline Lucro & 106 & 80 & 260 & 180 & 106 \\
\hline
\end{tabular}




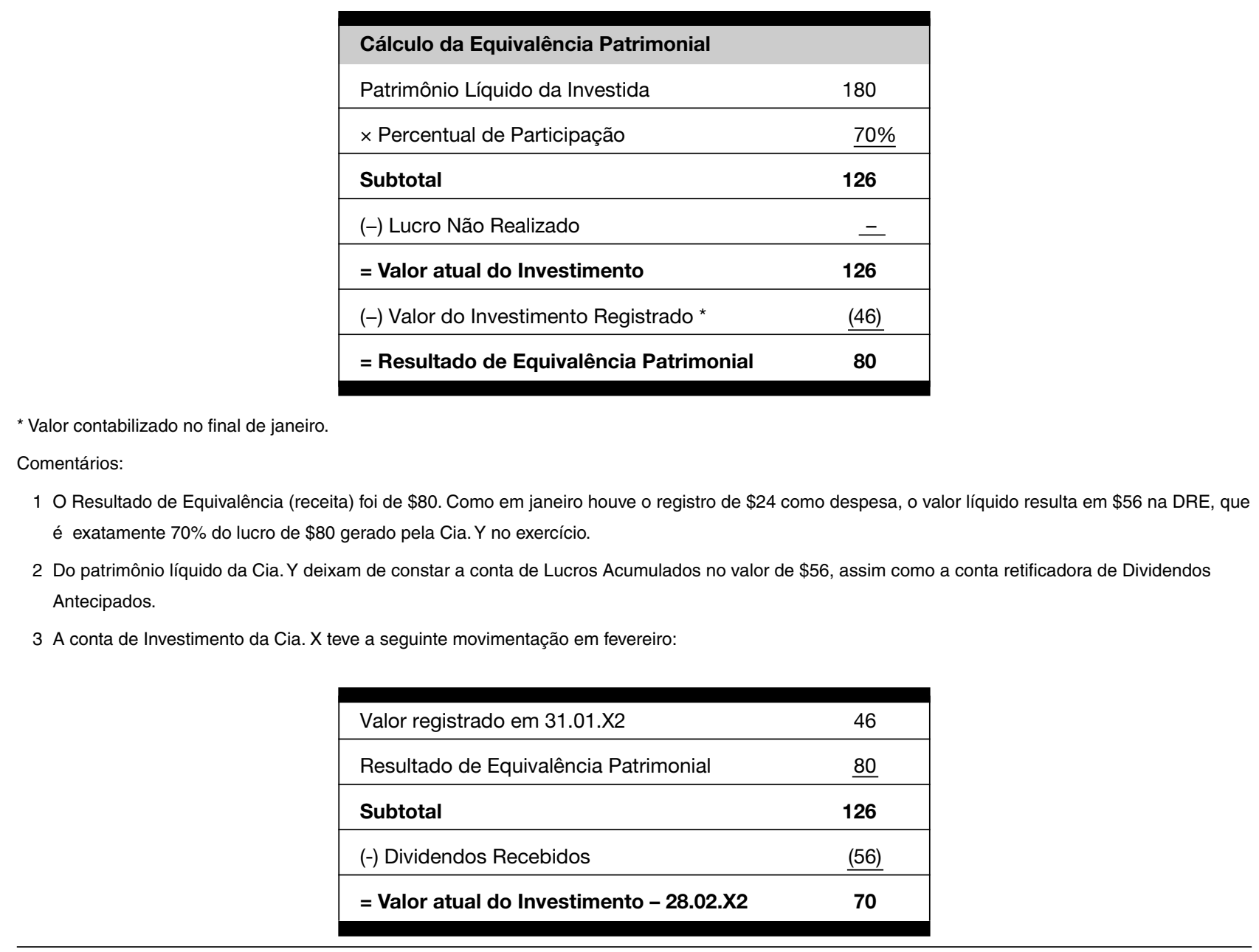

\section{CONSIDERACOOES FINAIS E CONCLUSOOES}

Os saldos e as operações realizadas entre empresas de um mesmo grupo devem ser eliminados das demonstrações contábeis consolidadas. Quando há operações com lucros não realizados, essas eliminações são ainda mais necessárias e isso se torna um fator relevante para a análise da situação econômico-financeira do grupo consolidado. O objetivo dessa eliminação é espelhar o real valor do ativo adquirido de terceiros, já que o balanço consolidado deve apresentar os valores como se as empresas consolidadas fossem uma única empresa. As eliminações de vendas efetuadas para as empresas têm o mesmo sentido já que o que interessa são apenas as vendas realizadas para terceiros, pois são essas que geram resultado econômico para o grupo. Assim, este trabalho focalizou um assunto ainda não discutido pela classe contábil e nem na literatura técnica da área, qual seja: a forma de contabilização de distribuição de dividendos quando existem lucros não realizados. Do ponto de vista do princípio da Competência de Exercícios, a controladora não deveria registrar como baixa de investimentos os valores oriundos de distribuição de resultados que a controlada efetua sobre lucros não realizados. Isso representa uma impropriedade técnica nas práticas contábeis atuais e, não bastasse isso, ainda corre-se o risco de, em determinados casos, ter-se a conta de Investimentos em Controladas e Coligadas com o saldo negativo (credor).

Neste estudo, discutiram-se duas alternativas de tratamento para essa distribuição de lucro não realizado: na primeira, o registro na controladora é efetuado como "Dividendos Antecipados", dentro do grupo de Resultados de Exercícios Futuros, uma vez que efetivamente se refere a lucro que só se realizará nos exercícios seguintes; na investida, o registro seria em "Dividendos Antecipados", no Ativo Circulante ou Realizável a longo prazo, dependendo das expectativas de realização desse lucro. Demonstrou-se que essa alternativa deve ser descartada.

$\mathrm{Na}$ segunda alternativa, sugere-se que a controladora faça o registro da mesma forma que o proposto na primeira alternativa, mas para a investida 
os valores dos dividendos antecipados deverão ser tratados como conta retificadora do patrimônio líquido. Essa segunda opção se apresentou como mais consistente, pois preserva o valor real do patrimônio líquido da investida.

O estudo, também, demonstrou que a distribuição antecipada de dividendos não interfere nos saldos das contas nas demonstrações consolidadas, uma vez que se eliminam os investimentos da controladora contra o patrimônio líquido da controlada, mas poderá causar dificuldades de entendimento em relação à participação dos não controladores. Portanto, o reflexo do registro inadequado dos dividendos está restrito às demonstrações individuais da controladora e da controlada.

Por se tratar de assunto até aqui não discutido nos meios acadêmico e profissional e pela sua relevância, entende-se que deveria merecer a atenção das entidades responsáveis pelo estudo e implantação das normas contábeis brasileiras.

\section{REFERÊNCIAS BIBLIOGRÁFICAS}

BRASIL. Lei n. 6.404, de 15 de junho de 1976. Dispõe sobre as sociedades por ações.

COMISSÃO DE VALORES MOBILIÁRIOS - CVM. Instrução n. 247, de 27 de março de 1996. Dispõe sobre a avaliação de investimentos em sociedades coligadas e controladas e procedimentos para elaboração e divulgação das demonstrações contábeis consolidadas.

FIPECAFI - USP. Manual de contabilidade das sociedades por ações. 6. ed. São Paulo: Atlas, 2003.

KPMG Corporate Finance. Fusões \& Aquisições. Publicação disponível no site: http://www.kpmg.com.br - publicações. Acesso: Março de 2005.
LAKATOS, Eva M.; MARCONI, Marina A. Metodologia Científica, São Paulo: Atlas, 1982.

MARTINS, Eliseu. Iniciação à Equivalência Patrimonial Considerando Algumas Regras Novas da CVM (1a parte). São Paulo: IOB-Informações Objetivas - TC 38/97, 1997.

MARTINS, Gilberto de Andrade. Manual para Elaboração de Monografias e Dissertações. 2. ed. São Paulo: Atlas, 2000.

\section{BIBLIOGRAFIA COMPLEMENTAR}

FASB - Financial Accounting Standards Board. Original Pronouncements. New York: John Witey \& Sons. 1998, vol. I e II.

IASC - INTERNATIONAL ACCOUNTING STANDARDS COMMITTEE. IAS-27 - Demonstrações Contábeis Consolidadas e Contabilização dos Investimentos em Subsidiárias, reformulado em 1994

MACHADO, Itamar M. Consolidação das demonstrações contábeis quando ocorre aquisição do controle de empresas durante o exercício social. Dissertação de Mestrado em Controladoria e Contabilidade - FEA/USP. São Paulo, 2002.
Santos, Ariovaldo. Consolidação de Demonstrações Contábeis: Erro na contabilização quando existem Lucros NãoRealizados. Curitiba: Resumos dos Trabalhos do $28^{\circ}$ Encontro da Anpad - ENANPAD, 2004.

MARTINS, Eliseu. Quais Investimentos Devem Ser Avaliados Pela Equivalência Patrimonial? São Paulo: IOB - Informações Objetivas - TC - 34 e 35/97, 1997.

STANDERSKI, Wlademiro. Consolidação de Balanços de Empresas Nacionais e Multinacionais. São Paulo: Livraria Pioneira, 1976.

NOTA:

Endereço dos autores:

Universidade de São Paulo

Depto. de Contabilidade e Atuária da FEA

Av. Prof. Luciano Gualberto, 908 - Cidade Universitária

São Paulo - SP

05.508-900
Faculdade Ibmec

Rua Paraíba, 330

Belo Horizonte - MG

30.130-140 